The Tuberculosis Services, as at present constituted, have not sufficient staff to examine and test all the known contacts once, let alone investigate them thoroughly at intervals, during infancy and childhood. Nor have we, as yet, developed any adequate type of Institution into which "suspected" children could be admitted without branding them with the often erroneous diagnosis of tuberculosis. And yet it is at the stage when they are only "suspected" that we should deal with them. Once definitely diagnosed it is no longer correct to speak of "prevention," it is now a question of "treatment."

I think we want a new type of tuberculosis officer for this purpose and a new type of Institution, not instead of the efficient officers and the excellent Institutions that we already possess but in addition to them.

I should like to see "Child Contact Officers," preferably medical women, appointed to the staffs of some of our Dispensaries for the special investigation, observation, and "follow up" of the young children in tuberculous homes, and perhaps for their vaccination according to some approved method. I should like to see established, to receive the child cases "suspected" by these officers, a new type of Institution, with "crêche," "kindergarten," "summer camps" andi" hospital" sections; and fitted out with modern X-ray facilities.

It is hardly to be expected that Local Authorities should, as yet, undertake such a programme in addition to the heavy burden they already carry in connection with the segregation and treatment of tuberculosis.

But the organization of a Demonstration Unit on these lines would provide us with much needed information and would undoubtedly go far to guide us in. an important and almost unexplored field in tuberculosis prevention.

One thing is certain, that preventive effort, to be successful, must be concentrated upon the problem of infected homes.

\title{
MAL-DESCENT OF THE TESTIS, AND SOME OF ITS PROBLEMS.
}

\section{BY HAMILTON BAILEY, F.R.c.s.}

Surgeon, Royal Northern Hospital ; Consultant Surgeon, Essex County Council.

THERE are many problerns of interest connected with this subject, and I propose to discuss briefly some of them.

The Function of the Scrotum. - In man, at any rate, the testes fail to develup fully unless they are housed in the scrotum. If an imperfectly descended organ can be placed in the scrotum before puberty, or even shortly afterwards, providing there is no undue tension upon the cord and the blood supply is unimpaired that immature organ will develop. So long as it remains in the inguinal canal or the abdomen, development does not occur. The only explanation given for this arresting phenomenon is that the scrotum is a thermo-regulating mechanism. It is stated that for active spermatogenesis the testes must be kept at an even temperature, slightly below the normal body temperature, and that the scrotum, by virtue of its dartos muscle, provides a means of regulating temperature-for instance, when it is cold the dartos contracts and hugs the testes nearer the trunk. If man remained unclothed one could more readily accept this 
theory, but it has always seemed to me that under prevailing conditions the theory is unsatisfactory. I prefer to look upon the testis as an organ intolerant of pressure. In the scrotum, as nowhere else, it enjoys freedom, and without freedom from pressure it cannot mature. Perhaps by virtue of its rich sympathetic plexus, pressure reflexly causes the testicular blood supply to be cut down and the organ hibernates. Conversely, when the testis is suspended in the scrotum, the gentle undulations of the ever-contracting and relaxing dartos may call forth a vasodilator reflex and the fully nourished secretory cells increase and multiply.

The Descent of the Testis.-The gubernaculum, consisting of activity proliferating cells with large ovoid nuclei, grows through the inguinal region, reaching its maximal development about the seventh month of fœtal life. At this time the distal end of the gubernaculum can be seen spreading out in a fan-shaped manner into six digitations. One of these digitations passes towards the saphenous opening; another tracks towards Poupart's ligament; a third makes its way towards the pubis, while the remainder pass respectively to the perinæum, to the root of the penis, and to the scrotum. In the human fotus the best developed digitation is the scrotal, and it is along this path that the testis normally proceeds, to reach its destination just before birth. In the fotal pig the gubernaculum's largest digitation can be traced to the perinæum, where the boar's testis is normally situated. Clinically an ectopic testis is found usually at one of the termini of the accessory gubernacular digitations. All this is very suggestive, and it shows that the gubernaculum determines the path which the organ takes, but it does not explain how the testis descends. In my student days it was taught that the guber-o naculum pulls, or rather by its later atrophy, drags the testis downwards, but this can be disproved by a simple demonstration. If an incision is made in the inguinal canal of a new-born male subject it can be shown that the distal end of the gubernaculum is attached, not to the scrotum, but to the coverings of the testis. Without a fixed point upon which to act it is inconceivable that the gubernaculum under any circumstances can assert traction upon the testis. The force which expels the organ must therefore be sought elsewhere. Because during the later months of fotal life the gut enlarges and becomes distended with meconium, it has been suggested that the intra-abdominal pressure rises and by the eighth month the pressure is sufficient to squeeze the testes through the abdominal wall. This does not explain why the left testis descends somewhat before the right nor can it be regarded in other respects as an entirely satisfactory hypothesis. So long as there is uncertainty as to how or why the testis descends problems connected with mal-descent will be more difficult to clarify.

Does Late Descent ever Occur.-Testes at one time in the scrotum and at another pulled up into the abdominal cavity are normal to some species, for instance, in the bat, rabbit and hedgehog the testes only migrate to the scrotum during the breeding season. There is a widespread and deep-rooted belief that if a young boy with a mal-descended testis is left alone the organ will drop into the scrotum at puberty. I have even encountered a few cases where a concomitant hernia had been treated by operation early in life, but no attempt had been made to bring down the testis-proof, indeed, of an implicit trust in the doctrine of late descent. Examples of patients and their hopeful parents waiting in vain are plentiful, but it has not been my lot to encounter a single instance of descent after the second year. It is necessary to emphasize here an important definition. An imperfectly descended testis is one which 
cannot be made to touch the bottom of the scrotum. In infant boys contraction of the cremaster sometimes pulls the testis temporarily into the inguinal canal, and this often deceives the casual clinician.

The Hazards of Mal-descent.-The main disadvantages of cryptorchidism are obvious. It is said that transient spermatogenesis occurs occasionally in imperfectly descended organs, but for all practical purposes the cryptorchid is sterile. As the years of manhood approach stigmata of degeneration often becomes manifest. Cryptorchidism is frequently a tragedy resulting in one more half-wit in the community.

Cryptorchidism is relatively rare. Unilateral failure to descent is ten times more common, and because the right testis passes through the inguinal region a little later than the left, it is the right testis which is usually retained.

Hernia.-Approximately 75 per cent. of imperfectly descended testes are complicated by an associated inguinal hernia--sufficient reason in itself, one would think, for advising operation.

Torsion occurs far more frequently in the mal-descended organ, and this acute complication is sufficiently common to warrant serious consideration.

Pain.-An imperfectly descended testis, particularly one situated in the inguinal canal, is liable to be painful. The pain usually comes on in attacks, and is either due to subacute torsion or to traumatism, which an organ in this situation is particularly liable.

Malignancy.-For years controversy has raged around the question of mal-descent in relation to malignant testis. Some competent observers are quite convinced that if the organ is not in the scrotum the liability to malignancy is increased greatly. A conservative summing up of the position would dictate that there is at least a slight increased tendency to neoplastic formation.

The hazards of mal-descent are considerable. If performed skilfully at the proper time, orchidopexy, not a dangerous procedure, offers important advantages and safeguards the patient against definite risks.

The Age at which the Operation should be Performed.-Years ago, Mr. Jacobson, whose "Indications for Operation" are always instructive and refreshing, while himself advocating earlier operation, stated "that most French surgeons advised deferring operation until the age of about 16." The teaching of the old French masters seems to have taken root and still lingers up and down this country. Let us examine this pernicious practice. If ten cases of imperectly descended testes are operated upon above the age of $1_{5}$, seven are likely to be failures because by this time it is usually impossible to free the constituents of the spermatic cord sufficiently to bring the testis down without tension. Such a high percentage of failures naturally brings orchidopexy into disrepute, and it is the operation, rather than the delay in performing it, which is blamed. In order to counteract this disastrous doctrine, surgeons who have interested themselves in this deformity are unanimous in advising a much earlier operation. There are a few who consider that the best results will be obtained if the testis is placed in the scrotum during infancy. The majority, however, would agree that unless a large concomitant hernia makes the operation during very early life almost a necessity, that the age of election for orchidopexy is between the 7 th and IIth years.

The Obstructing Agent to Scrotal Replacement.-Nearly always it will be found that the vas is long enough to allow the organ to be placed in the bottom of the scrotum. It is the spermatic vessels which obstruct replacement. Their careful dissection from 
the retroperitoneal tissues for a considerable distance allows the organ to be brought down when, before such a dissection, the proposition seemed hopeless. There is abundant evidence that the nutrition of the testis is dependant upon the integrity of the spermatic vessels, yet in some current text-books and works on operative surgery it is stated that in cases of difficulty these structures may be divided. Unless this teaching is entirely eradicated the prestige of orchidopexy is bound to suffer.

Multitudinous Methods of Orchidopexy.-There is hardly, if indeed there is, an operation in surgery where there are so many different methods of performance as that of orchidopexy. Advocates of a particular method are able to show that in their hands the operation is highly successful. When one critically examines the various methods, the main variation rests in the manner in which the organ is, as it were, splinted in the scrotum. The factor common to all showing a large percentage of successes is careful and thorough mobilization, particularly of the spermatic vessels. Without doubt this is the key-note of success and the method by which the organ is held in the scrotum is of secondary importance.

Conclusions :-

(I) The testis is an organ intolerant of pressure and for its proper development must be suspended in a loose sac-the scrotum.

(2) The gubernaculum prepares the path for the testis to descend, but the force which expels the organ from the abdomen must be sought for elsewhere.

(3) Natural descent after the second year is exceedingly rare.

(4) The age of election for performing orchidopexy is between the 7 th and IIth years.

(5) If the spermatic vessels are divided atrophy of the testis is inevitable.

(6) The common factor in the numerous methods of performing successful orchidopexy is thorough mobilization of the spermatic vessels without injuring them.

REFERENCES.

[1] Wangensteen, O. H. Arch. Surg., 1927, 663.

[2] Arey, L. B. "Developmental Anatomy," 1930.

[3] Goetsch, A. Amer. Journ. Surg., 1931, 63.

[4] JACoBson. "Operations of Surgery." Sixth Edition. 1915.

[5] Browne, Denis. Lancet, 1933, i, 460.

\title{
THE TECHNIQUE OF ALKALI THERAPY IN CASES OF B.C.C. PYELITIS
}

\author{
BY A. ARNOLD OSMAN, D.s.C., F.R.C.P.,
}

Consulting Physician to St. Alfege Hospital, Greenwich, and Physician to Queen Mary's Hospital, London, $E$.

THOUGH alkalies have long been used in the treatment of acute and subacute infections of the urinary tract with Bacillus coli communis, and are almost universally regarded as the most potent agents for this purpose, experience shows that in a considerable proportion of cases the full benefit to be derived from their use is not attained owing to faulty technique in their administration. To give even fairly large doses of sodium bicarbonate and/or potassium citrate by mouth, and to rely on the urine turning red 